\title{
Eenvoudiger wordt het er niet op...!
}

\section{Commentaar}

\author{
Hans Marks
}

Analysetriangulatie als procedure om de kwaliteit van kwalitatief onderzoek te verhogen is niet zonder problemen (Mason, 2002: 190-191). De insteek die Van Staa en Evers nemen om de lastige en tijdrovende analysemethoden van kwalitatief onderzoek te omzeilen, lijkt daarom niet bruikbaar voor praktijkgerichte kwalitatieve onderzoeksprojecten. Het is meer een procedure om de vaak rechtlijnige resultaten van onderzoekers binnen de 'academie' aan de kaak te stellen en een pleidooi voor een complexere afweging bij het gebruik en de presentatie van resultaten uit een kwalitatief onderzoek.

Het gebruik van verschillende analysestrategieën betekent dat uit één en dezelfde ruwe dataset verschillende soorten analyseerbare data worden gegenereerd. Bijvoorbeeld in een analyse gericht op taal, taalgebruik en metaforen worden andere data geanalyseerd dan in een analyse over het verloop van een dialoog of de opbouw van verhalen. Niet alleen de analyseerbare data zijn anders, maar tevens de verschijnselen waar ze naar verwijzen. Gaat het bij de ene analysestrategie om de achterliggende en impliciete structuren van de taal die verwijzen naar mentale houdingen in het dagelijks leven, bij het verloop van een dialoog of de opbouw van een verhaal kan het gaan om de bewuste representatie van het Self. Hier stoten we op de verschillende zijnswerkelijkheden die impliciet aanwezig zijn in alle datasets. De ene analysestrategie spreekt een andere zijnswerkelijkheid aan dan de andere analysestrategie.

Dat met de voorgestelde 'thick analysis' via analysetriangulatie meer transparantie wordt bereikt - of de afgezwakte vormen van gefundeerde theoriebenadering worden verbeterd - lijkt mij dan ook niet voor de hand te liggen.

Transparantie in de procedure is überhaupt een lastig probleem in kwalitatieve en etnografische analyse, zelfs voor ingewijden. Dat heeft te maken met de open procedure die tijdens het onderzoek wordt gevolgd. Open betekent namelijk ook dat het een procedure is van vallen en opstaan, dat er vruchteloze zijwegen worden ingeslagen die het rapporteren niet waard lijken. Delen van de analyse lopen op niets uit. Van deze mislukkingen en teleurstellingen - of liever gezegd pogingen tot zingeving - leert een onderzoeker veel, waardoor de analyse inhoudelijk een niet verwachte richting ingaat. Mislukkingen zijn voortschrijdende inzichten. Om een volledige precieze en transparante reconstructie te maken van de inhoudelijke analyse moet daarom ook veel papier gebruikt worden. Uitgevers en redacteuren van tijdschriften zijn daar niet in geïnteresseerd, en het merendeel van het academische publiek evenmin. Die laatste zijn vooral geïnteresseerd in de resultaten van het onderzoek op vakgebied en thematiek: de nieuwe typologie, variatie of theoretische samenhangen. Het resultaat van deze interne en externe eigenschappen van kwalitatief en etnografisch onderzoek is dat de methodologische logica van een 
onderzoek slechts op een gereduceerde manier in artikel of boek aan bod komt. Of we hiermee moeten volstaan, is natuurlijk een andere vraag, en het stellen van die vraag pleit voor de poging die Van Staa en Evers ondernemen om meer helderheid te verkrijgen in de complexiteit van kwalitatief onderzoek.

\title{
Literatuur
}

Mason, Oliver J. (2001, October). The application of mindfulness meditation in mental health: can protocol analysis help triangulate a grounded theory approach? 25 paragraphs]. Forum Qualitative Sozialforschung / Forum: Qualitative Social Research [On-line Journal], 3(1).

\section{Reactie op een strategie om de kwaliteit van de analyse te verhogen}

\author{
Hennie Boeije
}

Het essay van AnneLoes van Staa en Jeanine Evers is bijzonder prikkelend. Ze streven naar een verbetering van de kwaliteit van de kwalitatieve data-analyse. De oplossing die ze voorstellen is analysetriangulatie. Na lezing heb ik twijfels bij de door hen geconstateerde matige kwaliteit van de analyse. Naar mijn idee hebben ze bepaalde verwachtingen van de uitkomsten van kwalitatief onderzoek en vinden ze dat veel onderzoek niet aan die verwachtingen voldoet. Daarnaast maak ik kanttekeningen bij de oorzaken die ze aanwijzen voor een eventuele matige kwaliteit van de data-analyse. En omdat ik zowel aan het probleem als aan de oorzaken twijfel, weet ik ook niet waar analysetriangulatie nu precies een oplossing voor is. Het vorenstaande zal ik hierna uitwerken.

Volgens Van Staa en Evers is het probleem met de kwaliteit van de data-analyse dat 'dataanalyse vaak pragmatisch wordt ingestoken en wordt versimpeld tot een oppervlakkige thematische analyse'. Later noemen ze dat 'een sterk afgezwakte vorm van open coderen'. In hun visie komt de thematische analyse er niet best van af; het is een simpele, makkelijke versie van iets wat veel complexer en moeilijker had moeten zijn. Maar is een thematische analyse per definitie wel minder waard?

In het redactioneel van dit nummer van KWALON beschrijven we een classificatie van de bevindingen van kwalitatief onderzoek (Sandelowski \& Barroso, 2003). De classificatie is gebaseerd op de mate van bewerking van de gegevens door de onderzoekers oftewel op basis van de analyse (figuur 1). Helemaal links bevinden zich studies waarin de data nauwelijks zijn bewerkt en helemaal rechts bevinden zich studies waar de gegevens het meest zijn geanalyseerd. 